\title{
Faktor yang Berhubungan dengan Perilaku Penggunaan Full Body Harness di Proyek Pembangunan Apartemen oleh PT. X
}

\section{Related Factors to the Behaviour of Using Full Body Harness in Apartment Construction Projects by PT.X}

\author{
Ratri Apsariningdyah ${ }^{1}$, Afif Amir Amrullah ${ }^{2}$, Terry Y.R. Pristya ${ }^{3}$ \\ Fakultas Ilmu Kesehatan, Universitas Pembangunan Nasional Veteran Jakarta, Indonesia
}

\begin{tabular}{l} 
ARTICLE INFO \\
\hline Article history \\
Received date \\
01 Oct 2020 \\
Revised date \\
12 Oct 2020 \\
Accepted date \\
25 Nov 2020 \\
\hline
\end{tabular}

Keywords:

Behavior;

Full body harness;

Working at height.

\section{Kata kunci:}

Perilaku;

Penggunaan full body harness;

Pekerja ketinggian.

\begin{abstract}
ABSTRAK
Working at height is an important component in construction work, using a Full Body Harness $(\mathrm{FBH})$ to prevent the risk of falling from a height. Needs an effort to control accidents in the workplace, that is by using an FBH. This study aims To see and learn the factors related to the behavior of the workers at height in using an FBH in the apartment project of X Company. This study method Using a cross-sectional design. Using a total sampling of 65 workers. This research shows that $81,5 \%$ using an $\mathrm{FBH}$. There is a correlation between knowledge ( $p$-value $=0,001)$, attitude ( $p$-value $=0,001$ ), OSH training ( $\mathrm{p}$-value $=0,001)$, and the availability of FBH (p-value $=0,001)$, but there is no correlation between the level of education $(p$-value $=1,000)$, and work period with the behavior of using an FBH. There is a correlation between behavior, OSH training, availability of FBH on apartment project at X Company of 2020. The worker should use their knowledge and behavior that are received from OSH training and the company must keep the availability of FBH for workers so it will support the worker's behavior in using an FBH.
\end{abstract}

Pekerja ketinggian memiliki tugas penting dalam pembangunan, penggunaan Full body harness diwajibkan karena tingginya risiko dan bahaya yang dapat terjadi seperti terjatuh dan tergelincir. Maka perlu dilakukan upaya pengendalian guna melindungi pekerja dari kecelakaan kerja, salah satunya dengan menggunakan Full body harness. Tujuan untuk melihat dan mempelajari faktor-faktor yang berhubungan dengan perilaku dalam penggunaan Full body harness pada pekerja ketinggian di Apartemen oleh PT X Tahun 2020. Metode penelitian ini menggunakan desain studi cross sectional. Sampel penelitian menggunakan total sampling yaitu sebanyak 65 pekerja. Hasil penelitian menunjukan sebanyak 81,5\% menggunakan Full Body Harness. Terdapat hubungan antara pengetahuan $(p$-value $=0,001)$, sikap $(p$-value $=0,001)$, pelatihan K3 $(p$-value $=0,001)$, dan ketersediaan Full body harness ( $p$-value $=0,001)$. Sedangkan tidak terdapat hubungan antara tingkat pendidikan ( $p$-value $=1,000)$ dan masa kerja $(p$-value $=0,160)$ dengan perilaku penggunaan Full Body Harness. Disimpulkan hubungan antara pengetahuan, sikap, pelatihan K3 dan ketersediaan Full Body Harness dengan perilaku penggunaan Full Body Harness di Proyek Pembangunan Apartemen oleh PT X Tahun 2020. Pekerja dapat mempertahankan pengetahuan dan sikap yang diperoleh dari pelatihan dan didukung dengan ketersediaan Full body harness sehingga dapat menunjang perilaku dalam penggunaan Full body harness.

\section{Corresponding Author:}

Ratri Apsariningdyah

Fakultas Ilmu Kesehatan, Universitas Pembangunan Nasional Veteran Jakarta, Indonesia

Email: ratriapsariningdyah13@gmail.com

\section{PENDAHULUAN}

Undang-undang Republik Indonesia No.

13 Tahun 2003 tentang Ketenagakerjaan menyebutkan dalam pasal 86 ayat 1 setiap pekerja/buruh mempunyai hak untuk mendapatkan perlindungan atas keselamatan dan kesehatan kerja dilanjutkan dalam pasal 86 ayat 2 
bahwa melindungi keselamatan pekerja/buruh guna mewujudkan produktivitas kerja yang optimal perlu dilakukan upaya keselamatan dan kesehatan kerja (Kementerian Ketenagakerjaan Republik Indonesia, 2003).

Keselamatan dan Kesehatan Kerja (K3) merupakan salah satu cara keselamatan dan kesehatan kerja di lingkungan kerja dengan tujuan untuk meningkatkan kualitas hidup serta meningkatkan kreativitas saat bekerja. Sehingga, hal tersebut dapat berdampak baik pada keuntungan perusahaan (Yuliandi dan Ahman, 2019). Menghadapi era saat ini, penerapan keselamatan sangat diperlukan karena merupakan upaya sebagai perlindungan tenaga kerja saat berinteraksi dengan pekerjaannya. Keselamatan pekerja adahal penting bagi perusahaan, karena hal tersebut adalah kunci dari keberhasilan sebuah perusahaan untuk dapat memajukan perusahaan di bidang K3. Namun, saat ini masih banyak pekerja yang mengalami kecelakaan kerja di perusahaannya (Lailatus, 2017).

International Labor Organization (ILO), (2018) menyebutkan bahwa terdapat 2,87\% kematian yang disebabkan oleh kecelakaan kerja. Rata-rata kematian di Eropa yang disebabkan oleh kecelakaan kerja sejumlah 2 orang per hari, Tahun 2017 terdapat 123.041 kasus kecelakaan kerja, sedangkan pada tahun 2018 terdapat 173.105 kasus kecelakaan kerja (BPJS Ketenagakerjaan, 2019). Pada tahun 2015, jumlah kecelakaan kerja mencapai 105.182 kasus. Berdasarkan angka kejadian tersebut, sebanyak 38\% kecelakaan terjadi pada pekerja yang jatuh dari ketinggian (ISC Safety School, 2017).

Pada dasarnya, PT X sudah menetapkan dan menerapkan peraturan serta ketentuan keselamatan dan kesehatan kerja. Hanya saja upaya-upaya yang diberikan masih menjadi suatu hal yang dikesampingkan oleh para pekerja saat bekerja. Menurut Mokhtar dalam Lagata, (2015) menyebutkan bahwa ketidakinginan pekerja menggunakan APD pada saat bekerja disebabkan beberapa faktor, yaitu membatasi penglihatan dan pergerakan pada saat bekerja dan juga kurangnya pengawasan oleh pihak manajemen.

Berkaitan dengan risiko $\mathrm{K} 3$, pengendalian risiko dilakukan pada dasarnya untuk mengurangi kemungkinan atau keparahan yang dapat terjadi, yaitu diantaranya: eliminasi, substitusi, rekayasa teknik, pengendalian administratif dan alat pelindung diri (APD). Pada dasarnya hirarki kontrol mendefinisikan urutan dan mempertimbangkan kontrol yang dapat diterapkan oleh perusahaan. Umumnya tiga tingkat kontrol pertama adalah kontrol yang paling diinginkan, namun tiga tingkat tersebut tidak selalu mungkin untuk diterapkan karena harus mempertimbangkan manfaat, keandalan, dan biaya. Alat Pelindung Diri (APD) adalah bentuk proteksi pada pada pekerja di lingkungan pekerjaannya (Mahendra, 2016).

Rudyarti dalam Subing, (2018) menyatakan bahwa penggunaan APD adalah pengendalian tahap kerja tahap akhir. Namun berdasarkan faktanya, banyak pekerja yang tidak menggunakan APD walaupun sudah mengetahui besar manfaat penggunaan APD pada saat bekerja. Kurangnya kesadaran pekerja mengenai penyebab serta risiko kecelakaan kerja, sehingga perilaku tenaga kerja tampak seperti mengabaikan penggunaan APD. Dengan demikian, kurangnya kesadaran pekerja memperlihatkan bahwa masih banyak pekerja yang hanya fokus pada hasil kerja mereka dan bukan pada keselamatan saat bekerja (Vesta, 2012).

Peraturan Menteri Tenaga Kerja dan Transmigrasi tahun 2010 dalam pasal 1 menyatakan alat yang mampu melindungi pekerja yang berfungsi menutupi sebagian atau seluruh tubuh dari hal yang membahayakan dirinya maupun orang lain di lingkungan tempat kerja. (Kemennakertrans, 2010). Bekerja di ketinggian menjadi salah satu penyebab terjadinya cedera besar dikarenakan oleh beberapa faktor seperti lokasi bekerja yang berbahaya dan pekerja yang tidak berpengalaman, perusahaan harus mengambil langkah-langkah untuk mengurangi risiko pekerja terjatuh dari ketinggian (ISC Safety School, 2017).

Perilaku pekerja dalam penggunaan APD sangat penting sebagai langkah pencegahan dari kelecelakaan kerja dan mengamankan lingkungan kerja. Sehingga sangat diperlukan komitmen dari perusahaan, manajemen dan pekerja dalam K3. Full Body Harness adalah Alat Pelindung Diri (APD) yang dipasang pada tubuh untuk menangkap kekuatan di bahu, paha dan panggul sehingga pada saat mekanik terjatuh maka akan tergantung pada Body Harness yang terikat pada bagian alat berat (ISEA (International Safety Equipment Association), 2012).

PT X merupakan perusahaan kontraktor yang saat ini sedang menjalankan proyek pembangunan apartemen. Terdapat beberapa jenis pekerjaan di Proyek X tersebut dan tentunya terdapat berbagai bahaya dan risiko khususnya pada pekerja ketinggian. Bekerja di ketinggian harus memiliki sistem pengamanan dan perlindungan agar membantu dalam kelancaran pekerjaan, seperti SOP pekerjaan, alat pelindung diri dan perancah. Berdasarkan hasil observasi 
dan wawancara mendalam bersama pihak HSE pada studi pendahuluan ditemukan sebesar $25 \%$ dari 90 pekerja tidak menggunakan Full Body Harness yang sesuai khususnya pekerja bekisting. Pekerja bekisting memiliki tugas yang cukup penting dalam pembangunan, yaitu mengerjakan pemasangan tiang perancah dan pemasangan pondasi gedung yang memiliki risiko tinggi saat bekerja. Disebutkan dalam Peraturan Menteri Tenaga Kerja Nomor 9 Tahun 2016, pekerja yang bekerja di ketinggian wajib mengenakan full body harness karena termasuk jenis pekerjaan yang memiliki bahaya dan risiko yang cukup tinggi serta (Kementerian Ketenagakerjaan Republik Indonesia, 2016). Terdapat banyak risiko tinggi bagi pekerja ketinggian yang perlu diperhatikan di proyek X. Berdasarkan pemaparan di atas, penelitian ini akan membahas mengenai "Faktor-faktor yang berhubungan dengan perilaku penggunaan Full Body Harness di Proyek Pembangunan Apartemen oleh PT X Tahun 2020".

\section{METODE}

Faktor-faktor yang akan diteliti dibagi menjadi dua kelompok yaitu variabel dependen (terikat) dan variabel independen (bebas). Variabel dependen (terikat) yaitu perilaku dalam penggunaan Full Body Harness. Sedangkan variabel independen (bebas) terdiri dari pengetahuan, sikap, pendidikan, masa kerja, pelatihan K3 dan ketersediaan Full Body Harness.

Populasi yang digunakan dalam penelitian ini adalah seluruh pekerja proyek di bagian bekisting sebanyak 90 pekerja. Berdasarkan perhitungan sampel minimal menggunakan rumus slovin didapatkan hasil seharusnya sebanyak 74 pekerja. Pada awalnya, penelitian ini memilih menambah besaran sampel menjadi 90 orang. Akan tetapi, karena terjadi pandemi covid 19 yang memberikan dampak pada pengurangan jumlah pekerja di lapangan proyek PT X maka ditetapkan sampel menjadi 65 orang pada pekerja bekisting di Proyek Apartemen oleh PT X.

Pada penelitian ini data dianalisis menggunakan analisis univariat untuk distribusi frekuensi dan analisis bivariat untuk mengetahui hubungan antara dua variabel dengan menggunakan uji chi-square dan Fisher Exact.

Pertanyaan diajukan melalui angket dan lembar observasi. Pernyataan dan pertanyaan merupakan hasil dari modifikasi beberapa penelitian. Pertanyaan tentang pengetahuan berisi 15 soal dengan bentuk pertanyaan tertutup yaitu pilihan ganda dan benar atau salah. Jawaban benar akan diberi nilai 1, sedangkan jawaban yang salah akan diberi nilai 0 . Hasil dari angket tersebut akan dikategorikan menjadi pengetahuan baik, dan kurang.

Pertanyaan mengenai sikap pada pekerja mengenai bekerja di ketinggian dan Full Body Harness berisi 15 buah pertanyaan dengan bentuk pertanyaan tertutup. Pilihan mencakup SS (Sangat Setuju), S (Setuju), TS (Kurang Setuju) dan STS (Sangat Tidak Setuju) yang mana setiap pilihan diberi nilai berskala 1-4.

Pertanyaan mengenai pelatihan K3 yang dilakukan oleh pekerja berisi 2 buah pertanyaan dengan bentuk pertanyaan tertutup. Dengan pilihan Ya dan Tidak.

Lembar observasi digunakan untuk mengobservasi atau mengukur perilaku pekerja, yang digunakan sebagai perekam data guna memperoleh gambaran mengenai perilaku pekerja secara alamiah tanpa manipulasi. Pada penelitian ini, lembar observasi digunakan melihat perilaku pada pekerja ketingian dalam menggunakan Full Body Harness pada saat bekerja apakah pekerja menggunakan Full Body Harness secara lengkap atau tidak.

Penelitian ini telah disetujui oleh tim komite etik penelitian kesehatan (KEPK) yang dilakukan di Universitas Pembangunan Nasional "Veteran" Jakarta dengan nomor surat B/2550/VI/2020/KEPK.

\section{HASIL}

Tabel 1. Distribusi Frekuensi Variabel

\begin{tabular}{lll}
\hline \multicolumn{1}{c}{ Variabel } & f & \% \\
\hline Perilaku & & \\
$\quad$ Tidak & 12 & 18,5 \\
Menggunakan & 53 & 81,5 \\
$\quad$ Menggunakan & & \\
Pengetahuan & 12 & 18,5 \\
$\quad$ Kurang & 53 & 81,5 \\
$\quad$ Baik & & \\
Sikap & 13 & 20 \\
$\quad$ Buruk & 52 & 80 \\
$\quad$ Baik & & \\
Pendidikan & 20 & 30,8 \\
$\quad$ Rendah & 45 & 69,2 \\
$\quad$ Tinggi & & \\
Masa Kerja & 17 & 26,2 \\
$\quad$ 0-6 bulan & 48 & 73,8 \\
$\quad>6$ bulan & & \\
Pelatihan K3 & 18 & 27,7 \\
$\quad$ Tidak & 47 & 72,3 \\
$\quad$ Ya & & \\
Ketersediaan FBH & 12 & 19,0 \\
$\quad$ Tidak & 51 & 81,0 \\
$\quad$ Ya & & \\
\hline
\end{tabular}


Pekerja bekisting di Proyek Pembangunan Apartemen mayoritas sudah menggunakan Full Body Harness pada saat bekerja sebanyak 53 pekerja $(81,5 \%)$ dari 65 pekerja. 53 pekerja $(81,5 \%)$ sudah memiliki pengetahuan yang baik dalam penggunaan Full Body Harness. Sikap baik dimiliki oleh 52 pekerja $(80 \%)$ pada saat melaksanakan pekerjaanya. Sebanyak 45 pekerja $(69,2 \%)$ memiliki tingkat pendidikan yang tinggi sedangkan $20(30,8 \%)$ dari 65 pekerja memiliki tingkat pendidikan rendah. Mayoritas pekerja sudah pernah mengikuti pelatihan K3 sebanyak 47 pekerja $(72,3 \%)$, dan berpendapat bahwa pelatihan K3 dapat mempengaruhi perilaku dalam bekerja. 51 pekerja $(81 \%)$ pekerja bekisting juga menjawab bahwa ketersediaan Full Body Harness di perusahaan sudah mencukupi kebutuhan, mudah didapatkan serta diganti jika Full Body Harness tidak layak pakai.

Tabel 2. Hubungan Pengetahuan, Sikap, Pendidikan, Masa Kerja, Pelatihan K3, dan Ketersediaan Full Body Harness dengan Perilaku Penggunaan Full Body Harness

\begin{tabular}{|c|c|c|c|c|c|c|c|}
\hline \multirow{3}{*}{ Variabel } & \multicolumn{4}{|c|}{$\begin{array}{r}\text { Perilaku } \\
\end{array}$} & \multirow{3}{*}{$\mathbf{n}$} & \multirow{3}{*}{$\%$} & \multirow{3}{*}{ p-value } \\
\hline & \multicolumn{2}{|c|}{$\begin{array}{c}\text { Tidak } \\
\text { Menggunakan FBH }\end{array}$} & \multicolumn{2}{|c|}{$\begin{array}{c}\text { Menggunakan } \\
\text { FBH }\end{array}$} & & & \\
\hline & n & $\%$ & n & $\%$ & & & \\
\hline \multicolumn{8}{|l|}{$\overline{\text { Pengetahuan }}$} \\
\hline Kurang & 11 & 91,7 & 1 & 8,3 & 12 & 100 & 0,001 \\
\hline Baik & 1 & 2 & 52 & 88 & 53 & & \\
\hline \multicolumn{8}{|l|}{ Sikap } \\
\hline Buruk & 11 & 15,4 & 2 & 84,6 & 13 & 100 & 0,001 \\
\hline Baik & 1 & 1,9 & 51 & 98,1 & 52 & & \\
\hline \multicolumn{8}{|l|}{ Pendidikan } \\
\hline Rendah & 4 & 20 & 16 & 80 & 20 & 100 & 1,000 \\
\hline Tinggi & 8 & 17,8 & 37 & 82,2 & 45 & & \\
\hline \multicolumn{8}{|l|}{ Masa Kerja } \\
\hline $0-6$ bulan & 1 & 5,9 & 16 & 94,1 & 17 & 100 & 0,160 \\
\hline$>6$ bulan & 11 & 22,9 & 37 & 77,1 & 48 & & \\
\hline \multicolumn{8}{|l|}{ Pelatihan } \\
\hline Tidak & 11 & 61,1 & 7 & 38,9 & 18 & 100 & 0,001 \\
\hline $\mathrm{Ya}$ & 1 & 2,1 & 46 & 97,9 & 47 & & \\
\hline \multicolumn{8}{|c|}{ Ketersediaan FBH } \\
\hline Tidak & 8 & 57,1 & 6 & 42,9 & 14 & 100 & 0,001 \\
\hline $\mathrm{Ya}$ & 4 & 7,8 & 47 & 92,9 & 51 & & \\
\hline
\end{tabular}

Berdasarkan tabel 2, dapat diketahui bahwa banyak pekerja memiliki pengetahuan yang baik sehingga membentuk perilaku dalam penggunaan Full Body Harness yaitu sebesar $98 \%$ p-value 0,001 ( $p$-value $>0,05$ ). Hal tersebut membuktikan bahwa terdapat keterkaitan antara tingkat pengetahuan pekerja dengan perilaku penggunaan Full Body Harness.

Pada variabel sikap mayoritas pekerja memiliki sikap yang baik yaitu sebesar $98,1 \%$. Didapatkan nilai $p$-value 0,001 ( $p$-value $<0,05$ ). Hal tersebut menunjukkan bahwa terdapat hubungan antara sikap pekerja dengan perilaku penggunaan Full Body Harness.

Pada variabel pendidikan dapat diketahui bahwa mayoritas pekerja memiliki tingkat pendidikan tinggi sebesar $82,2 \%$ daripada pekerja dengan tingkat pendidikan rendah lainnya sebesar $80 \%$. Hasil $p$-value dari variabel tingkat pendidikan adalah $p$-value 1,000 ( $p$ value $<0,05)$. Hal tersebut menunjukkan bahwa tidak terdapat hubungan antara tingkat pendidikan dengan perilaku penggunaan Full

\section{Body Harness.}

Masa kerja pada pekerja bekisting sebagian besar pekerja mempunyai masa kerja lebih dari 6 (enam) bulan sebesar 77,1\% daripada pekerja dengan masa kerja 0-6 bulan sebanyak $16(94,1 \%)$ didapatkan nilai $p$-value 0,160 ( $p$-value $<0,05$ ), nilai yang dihasilkan lebih besar dibandingkan dengan nilai $p$-value. Sehingga tidak ada keterkaitan yang berarti antara masa kerja dengan perilaku penggunaan Full Body Harness.

Pekerja bekisting yang melakukan pelatihan K3 lebih banyak berperilaku dalam penggunaan Full Body Harness sebesar 97,9\%. Berdasarkan data tersebut didapatkan hasil $p$ value 0,001 Hal tersebut menunjukkan bahwa terdapat hubungan antara pelatihan $\mathrm{K} 3$ dengan perilaku penggunaan Full Body Harness.

Pada variabel ketersediaan FBH, diketahui pekerja 92,2\% menjawab bahwa ketersediaan Full Body Harness yang ada di perusahaan mempengaruhi perilaku dalam penggunaan Full Body Harness, Berdasarkan jawaban tersebut 
didapatkan nilai $p$-value 0,001 yang berarti bahwa terdapat hubungan antara ketersediaan Full Body Harness dengan perilaku penggunaan Full Body Harness.

\section{PEMBAHASAN}

\section{Hubungan Pengetahuan dengan Perilaku Penggunaan Full Body Harness}

Berdasarkan data yang terdapat pada tabel 2, mayoritas responden berada pada tingkat pengetahuan yang baik dengan menggunakan Full Body Harness saat bekerja. Berdasarkan uji statistik telah didapatkan hasil $0,001 \quad(p-$ value $<0,05$ ). Hasil tersebut menunjukan terdapat korelasi perilaku dengan penggunaan Full Body Harness.

Hasil penelitian ini sejalan antara tingkat pengetahuan dengan perilaku pemakaian Full Body Harness dengan penelitian yang dijalankan oleh Iskandar dan Handayani (2018) bahwa pekerja yang mempunyai pengetahuan baik bekerja dengan menggunakan APD.

Jika penerimaan perilaku baru melalui porses yang disadari oleh pengetahuan, kesadaran dan sikap yang positif, maka perilalu tersebut akan bersifat langgeng (long lasting) daripada perilaku yang tidak didasari oleh pengetahuan (Notoatmodjo, 2003).

\section{Hubungan Sikap dengan Perilaku Penggunaan Full Body Harness}

Mayoritas pekerja memiliki sikap baik didapatkan nilai $p$-value 0,001 ( $p$-value $<0,05)$. Hasil tersebut menunjukan adanya korelasi antara sikap dengan perilaku penggunaan Full Body Harness.

Penelitian ini sejalan dengan penelitian yang dilakukan oleh Liswanti tahun 2017 yang mengungkapkan bahwa terdapat keterkaitan signifikan antara sikap terhadap perilaku penggunaan APD. Hasil nilai $p$-value yang diperoleh adalah 0,004 ( $p$-value $<0,05)$.

Salah satu faktor yang mempengaruhi perilaku yang biasa dipandang yaitu sikap. (Fishbein dan Ajzen, 1977) mengatakan yaitu sikap bisa mempengaruhi perilaku melalui tahap dalam penetapan kesimpulan yang akurat dan berdasar, akibatnya 3 (tiga) hal, yaitu:

a. Perilaku bukan ditetapkan dengan sikap umum, melainkan sikap yang khusus akan perilaku tertentu;

b. Perilaku bukan sekedar dikontrol dengan sikap, namun saja dengan aturan-aturan yaitu tebtang apa yang orang lain dambakan supaya kita melakukan;

c. Sikap akan suatu perilaku bahu-membahu dengan aturan satu sisi membangun suatu ambisi atau keinginan untuk berperilaku khusus.

Hasil penelitian yang dilakukan sebanding dengan teori perilaku Bloom dalam Notoatmodjo (2003) yaitu perilaku melahirkan manfaat dari faktor predisposisi yakni faktor yang terdapat dalam diri perseorangan dan diperoleh sikap dari perseorangan.

\section{Hubungan Pendidikan dengan Perilaku Penggunaan Full Body Harness}

Pada variabel pendidikan, didapatkan $p$ value adalah 1,000 ( $p$-value $>0,05$ ) dari hasil tersebut yaitu tidak terdapat keterkaitan tingkat pendidikan dengan perilaku penggunaan Full Body Harness. Hal ini sejalanan dengan penelitian Iskandar dan Handayani (2018) yang menghasilkan nilai $p$-value 0,639 ( $p$-value $>0,05$ ) dan mengatakan tidak terdapat keterkaitan tingkat pendidikan dengan perilaku penggunaan APD.

Pekerja dengan tingkat pendidikan yang baik maka akan mudah dalam menerima informasi terkait yang akan diberikan. Menurut Notoatmodjo, (2014) pendidikan merupakan satu bagian kekhususan individu yang akan mempengaruhi penerimaan tenaga kerja terhadap perilaku baru yang dibutuhkan saat bekerja.

\section{Hubungan Masa Kerja dengan Perilaku Penggunaan Full Body Harness}

Hasil penelitian berdasarkan uji statistik menerangkan tidak terdapat korelasi masa kerja dengan perilaku penggunaan Full Body Harness $(p$-value $=0,160)$. Hal ini sejalan dengan penelitian yang dilakukan oleh Wekoyla (2012) pada variabel masa kerja didapatkan hasil pvalue adalah $0,965(>0,05)$, sehingga tidak terdapat hubungan antara masa kerja dengan perilaku penggunaan Alat Pelindung Diri (APD).

Puji, dkk, tahun 2017 menyatakan tidak terdapat keterkaitan masa kerja dengan kepatuhan dalam penggunaan APD. Secara teoritis masa kerja yang lama nyatanya bakal mencetuskan suatu kejenuhan atau kebosanan dalam bekerja. Sama halnya mengenai responden yang melaksanakan pekerjaan yang sama setiap harinya maka akan membangunkan kebosanan.

Menurut Septianingsih, (2017) masa 
kerja seseorang berkaitan dengan pengalaman orang tersebut, semakin lama seseorang bekerja maka akan lebih mengetahui lingkungannya dan mengetahui bagaimana cara bekerja secara aman. Kesimpulan dari uraian di atas adalah masa kerja yang telah dijalankan oleh pekerja tidak dapat menjanjikan bahwa pekerja yang lebih lama bekerja berperilaku yang baik dalam mengenakan Full Body Harness daripada pekerja yang baru.

\section{Hubungan Pelatihan K3 dengan Perilaku Penggunaan Full Body Harness}

Pelatihan K3 melahirkan keadaan yang cukup berarti untuk dibagikan bagi pekerja. Hasil penelitian menunjukkan bahwa terdapat hubungan antara pelatihan K3 dengan perilaku penggunaan Full Body Harness. Manfaat dilaksanakannya pelatihan K3 adalah agar pekerja dapat mengetahui dan memahami macam-macam bahaya pada saat melakukan pekerjaan dengan tidak menggunakan APD dan pekerja dapat mengaplikasikan dalam perilaku penggunaan APD. Dari data primer yang dikumpulkan selama penelitian, sebagian besar pekerja sudah mengikuti pelatihan K3. Namun, pelaksanaannya belum secara rutin dan menyeluruh. Berdasarkan hasil yang didapatkan untuk melihat hubungan antara pelatihan K3 dengan perilaku penggunaan Full Body Harness didapatkan $p$-value 0,001 ( $p$-value $>0,05$ ). Hasil tersebut diketahui bahwa terdapat hubungan antara pelatihan K3 dengan perilaku penggunaan Full Body Harness.

Penelitian ini sejalan dengan penelitian Raodhah dan Gemely, (2014) yang mengungkapkan terdapat korelasi pelatihan K3 dengan perilaku penggunaan APD. Hal ini berarti bahwa pekerja yang sudah menjajaki pelatihan $\mathrm{K} 3$ dapat mempengaruhi penggunaan APD saat bekerja.

Menurut Wexley \& Yuki dalam Dwiyanti dan Irlianti, (2014) berpendapat bahwa pekerja yang sudah lama bekerja semestinya melakukan sebaiknya dilakukan training pelatihan ulang pada pekerja.

\section{Hubungan Ketersediaan Full Body Harness dengan Perilaku Penggunaan Full Body Harness (FBH)}

Berdasarkan data primer yang sudah didapatkan sebagian besar pekerja menilai ketersediaan FBH di tempat kerja tersedia sesuai kebutuhan, mudah di dapatkan, layak digunakan dan mencukupi kebutuhan. Hasil analisis uji fisher exact didapatkan nilai $p$-value $0,001(p$ value $<0,05)$. Berdasarkan hasil penelitian yang dilakukan maka dapat didapatkan bahwa adanya korelasi ketersediaan Full Body Harness dengan perilaku penggunaan Full Body Harness.

Penelitian tersebut sejalan dengan penelitian yang dilakukan oleh Prasetyo (2015), yang menyatakan ketersediaan APD oleh perusahaan terhadap perilaku dalam pemakaian APD menunjukkan sebagian besar responden patuh dalam memakai APD dikarenakan telah tersedia alat pelindung diri. Hasil penelitian didapatkan nilai $p$-value 0,009 ( -value $<0,05$ ), yang artinya adalah terdapat pengaruh kesiapan APD terhadap perilaku pemakaian APD. Disebutkan juga bahwa ketersediaan APD lebih mempengaruhi perilaku dalam penggunaan APD.

Ketersediaan APD adalah faktor pendukung dalam perilaku penggunaan APD yang dapat mencegah terjadinya insiden dan risiko kerja di perusahaan. Jika perusahaan tidak menyiapkan APD maka perusahaan telah mencelakakan pekerja dari risiko kecelakaan kerja dan PAK. Maka dari itu, perusahaan harus menyiapkan APD sesuai dengan kebutuhan dari masing-masing setiap pekerjaan (Prasetyo, 2015).

\section{SIMPULAN}

Berdasarkan hasil observasi pada penelitian ini, jumlah pekerja pada pembangunan apartemen oleh PT X sebagian besar memiliki perilaku baik. Mayoritas pekerja mempunyai tingkat pengetahuan yang baik, sikap yang baik akan perilaku penggunaan Full Body Harness telah bekerja lebih dari enam bulan, sudah mengikuti pelatihan K3 dan setuju bahwa pelatihan K3 mempengaruhi perilaku pekerja saat melakukan pekerjaan, dan sebagian besar pekerja mengatakan bahwa ketersediaan Full Body Harness oleh perusahaan dengan kondisi yang layak, mudah didapatkan dan muncukupi dapat mempengaruhi perilaku dalam bekerja dengan menggunakan Full Body Harness.

Terdapat hubungan antara pengetahuan, sikap, pelatihan K3 dan ketersediaan Full Body Harness dengan perilaku dalam penggunaan Full Body Harness. Dan, tidak ada keterkaitan tingkat pendidikan dengan perilaku dalam penggunaan Full Body Harness. 


\section{DAFTAR PUSTAKA}

BPJS Ketenagakerjaan. (2019). Angka Kecelakaan Kerja Cenderung Meningkat, BPJS Ketenagakerjaan Bayar Santunan Rp 1,2 Triliun. https://www.bpjsketenagakerjaan.go.id/ber ita/23322/Angka-Kecelakaan-Kerja-

Cenderung.

Dwiyanti, E., \& Irlianti, A. (2014). Analisis perilaku aman tenaga kerja menggunakan model perilaku ABC (Antecedent Behavior Consequence). Indonesian Journal of Occupational Safety and Health,3(1), 3812.

Fishbein, M. and Ajzen, I. (1977). Belief, Attitude, Intention, and Behavior: An Introduction to Theory and Research. in Douglass, R. B. (ed.). Penn State University Press, pp. 130-132.

Iskandar, R. H., \& Handayani, S. (2018). Hubungan Faktor Predisposisi Dengan Perilaku Penggunaan Alat Pelindung Diri Di PT. PJB UBJ O\&M PLTU Indramayu. Afiasi: Jurnal Kesehatan Masyarakat, 3(2), 45-56.

ILO. (2018). Meningkatkan Keselamatan dan Kesehatan Pekerja Muda, Kantor Perburuhan Internasional., $\mathrm{CH}-1211$ Geneva 22, Switzerland. http://www.oit.org/wcmsp5/groups/public/ ---asia/---ro-bangkok/---ilojakarta/documents/publication/wcms_6 27174.pdf.

ISC Safety School. (2017). Kecelakaan Kerja Jatuh dari Ketinggian di Indonesia. https://www.indonesiasafetycenter.org/kno wledges/kecelakaan-kerja-jatuh-dariketinggian-di-indonesia.

ISEA (International Safety Equipment Association). (2012). Personal fall protection equipment. Anchor devices. p. 16415.

Kemennakertrans. (2010). Peraturan Menteri Tenaga Kerja dan Transmigrasi Republik Indonesia. Peraturan Menteri, pp. 1-69. https://jdih.kemnaker.go.id/data_puu/perat uran_file_310.pdf.

Kementerian Ketenagakerjaan Republik Indonesia. (2003). Undang-Undang Republik Indonesia No.13 Tahun 2003 tentang Ketenagakerjaan. http://www.kemenperin.go.id/kompete nsi/UU_13_2003.pdf.

Kementerian Ketenagakerjaan Republik Indonesia. (2016). Peraturan Menteri Ketenagakerjaan No. 9 tahun 2016 tentang
Keselamatan dan kesehatan kerja dalam pekerjaan di ketinggian. Jakarta.

Lailatus, S. (2017). Hubungan Pemakaian Alat Pelindung Diri ( APD ) dengan Kejadian Kecelakaan Kerja pada Pekerja Penderes di PTPN III Kebun Sei Silau Tahun 2017. [Skripsi]. Medan, Fakultas Kesehatan Masyarakat. Universitas Sumatera Utara. http://repositori.usu.ac.id/handle/12345 $6789 / 2121$.

Lagata, F. S. (2015). Gambaran Perilaku Penggunaan Alat Pelindung Diri (APD) pada Pekerja di Departemen Produksi PT. MARUKI INTERNASIONAL INDONESIA MAKASSAR TAHUN 2015. [Skripsi]. Makassar: UIN Alaudin Makassar. 5(1), pp. 643-654. doi: 10.1016/j.jbankfin.2017.09.006.

Mahendra, R. (2016). Hirarki Pengendalian Bahaya dalam OHSAS 18001:2007. ISO Center Indonesia. https://isoindonesiacenter.com/hierarkipengendalian-bahaya-dalam-ohsas 180012007/ Di akses pada : 04 Juli 2020.

Notoatmodjo, S. (2003). Pendidikan dan Perilaku Kesehatan. Jakarta: PT. Rineka Cipta.

Notoatmodjo, S. (2014). Ilmu Perilaku Kesehatan. 2nd ed. Jakarta: PT. Rineka Cipta.

Prasetyo, E. (2015). Pengaruh Pengetahuan, Sikap, dan Ketersediaan Alat Pelindung Diri (APD) Terhadap Kepatuhan dalam Menggunakan APD di Unit Coating PT. Pura Barutama Kudus. Jurnal Keperawatan dan Kesehatan Masyarakat Cendekia Utama. 2(3), pp. 526-535. https://jurnal.unimus.ac.id/index.php/p sn12012010/article/download/1633/16 85.

Puji, A.D., Kurniawan, B. dan Jayanti, S. (2017). Faktor-faktor yang Berhubungan dengan Kepatuhan Penggunaan Alat Pelindung Diri pada Pekerja Rekanan (PT.X) di PT Indonesia Power UP Semarang. Kesehatan Masyarakat, 5, pp. 20-31.

Raodhah, S. dan Gemely, D. (2014). FaktorFaktor Yang Berhubungan Dengan Penggunaan Alat Pelindung Diri Pada Karyawan Bagian Packer PT Semen Bosowa Maros Tahun 2014. Al-Sihah: Public Health Science Journal, IV, pp. 437-40.

Septianingsih, N. D. (2017). PENGARUH UPAH DAN LINGKUNGAN KERJA TERHADAP KINERJA KARYAWAN 


\section{DALAM PERSPEKTIF EKONOMI} ISLAM PADA CV. NATURAL PALEMBANG.[Skripsi]. Palembang: UIN Raden Fatah Palembang.

Subing, D. M. (2018). Hubungan Pengetahuan, Sikap, Dan Perilaku Penggunaan Alat Pelindung Diri Dengan Kejadian Kecelakaan Kerja Pada Tenaga Kerja Bangunan Di Perumahan Hajimena Lampung Selatan. [Skripsi]. Lampung: Universitas Kedokteran, Universitas Lampung.

Vesta, E. (2012). Gambaran Persepsi Pekerja Tentang Risiko Kecelakaan Kerja di Departemen Produksi dan Utility PT. Wilmar Nabati Indonesia Dumai Tahun
2012. Lingkungan dan Keselamatan Kerja, 1(1), 14645.

Wekoyla. (2012). Hubungan pengetahuan, sikap, pendidikan dan masa kerja bidan terhadap perilaku penggunaan alat pelindung diri pada tindakan pertolongan persalinan di Rumah sakit umum provinsi sulawesi tenggara dan rumah sakit umum kota kendari tahun 2012 [Skripsi]. Depok: Universitas Indonesia.

Yuliandi, C. D. dan Ahman, E. (2019). Penerapan Keselamatan dan Kesehatan Kerja (K3) di Lingkugan Kerja Balai Inseminasi Buatan (BIB) Lembang. Manajerial,18(2),pp.98109.

http://ejournal.upi.edu/index.php/manajeria $1 /$. 